\title{
Preferential elimination of chromosome 1D from homoeologous group-1 alien addition lines in hexaploid wheat
}

\author{
Monika Garg ${ }^{1}$, Hala M. M. Elamein ${ }^{1}$, Hiroyuki Tanaka ${ }^{1,2}$ \\ and Hisashi Tsujimoto ${ }^{1,2 *}$ \\ ${ }^{1}$ Laboratory of Plant Genetics and Breeding Science, United Graduate School of \\ Agricultural Sciences, Tottori University, Koyama, Tottori 680-8553, Japan \\ ${ }^{2}$ Laboratory of Plant Genetics and Breeding Science, Faculty of \\ Agriculture, Tottori University, Koyama, \\ Tottori 680-8553, Japan
}

(Received 5 June 2007, accepted 4 September 2007)

\begin{abstract}
Alien chromosome addition lines are useful genetic material for studying the effect of an individual chromosome in the same genetic background. However, addition lines are sometimes unstable and tend to lose the alien chromosome in subsequent generations. In this study, we report preferential removal of chromosome 1D rather than the alien chromosome from homoeologous group-1 addition lines. The Agropyron intermedium chromosome 1Agi (1E) addition line, created in the background of 'Vilmorin 27', showed loss of a part of chromosome 1D, thereby losing its HMW glutenin locus. Even in the case of Aegilops longissima and Ae. peregrina, the genomes of which are closer to the $\mathrm{B}$ genome than $\mathrm{D}$ genome, chromosome $1 \mathrm{D}$ was lost from chromosome $1 \mathrm{~S}^{\mathrm{l}}$ and $1 \mathrm{~S}^{\mathrm{v}}$ addition lines in cv. 'Chinese Spring' rather than chromosome 1B during transfer from one generation to another. A similar observation was also observed in the case of a chromosome $1 \mathrm{E}$ disomic addition line of Ag. elongatum and alloplasmic common wheat line with Ag. intermedium ssp. trichophorum cytoplasm. The reason for this strange observation is thought to lie in the history of wheat evolution, the size of chromosome $1 \mathrm{D}$ compared to $1 \mathrm{~A}$ and $1 \mathrm{~B}$, or differing pollen competition abilities.
\end{abstract}

Key words: wheat, alien chromosome addition lines, chromosome elimination, HMW glutenin, FISH

\section{INTRODUCTION}

Alien chromosome addition lines are useful genetic material for studying the effect of an individual chromosome in the same genetic background as well as being potential genetic resources for wheat breeding. They also serve as suitable materials for chromosome location of useful genes. However, addition lines are sometimes unstable and tend to lose the alien chromosome in subsequent generations. As a part of the National Bioresource Project-Wheat (NBPR-Wheat), we intensively collected wheat accessions with an alien chromosome then examined the chromosomes to provide appropriate research materials. While studying these addition lines, we observed many cases of alien chromosome elimination, varying from the expected 44 chromosomes to 43 or even

Edited by Koji Murai

* Corresponding author. E-mail: tsujim@muses.tottori-u.ac.jp
42 , which is the same as normal common wheat. In addition we often observed unexpected electrophoretic profile from the proteins of wheat and of the alien species.

In wheat, seed storage proteins were classified into two major components, the gliadins and the glutenins, and further glutenins into high-molecular-weight (HMW) glutenins and low-molecular-weight (LMW) glutenins (NietoTaladriz et al., 1994). Hexaploid wheat carries two subunits of HMW glutenin $\mathrm{x}$ - type (slow moving) and $\mathrm{y}$ type (fast moving). Both of the subunits are encoded by the $\mathrm{x}$ - and y-type genes in the Glu-1 loci located on the homoeologous group-1 chromosomes (Lawrence and Shepherd, 1981). As HMW glutenin subunits are major determinant of wheat end product quality and as it is easy to study by sodium dodecyl sulphate polyacrylamide gel electrophoresis (SDS-PAGE), we screened all the materials for glutenin profile. In the study, we often met with the cases of loss of chromosome-1D products, irrespective of the phylogenetical similarity between the alien 
and wheat chromosomes. Specific removal of some Dgenome chromosomes while retaining complete $\mathrm{A}$ and $\mathrm{B}$ genomes have been also reported in hexaploid lines that appeared spontaneously in octoploid Triticales (Dou et al., 2006). We report here this strange genetical phenomenon in cases of disomic addition lines and discuss the possible reasons.

\section{MATERIALS AND METHODS}

Plant materials The plant materials used in this study included 177 disomic addition lines of common wheat (Triticum aestivum) containing a chromosome from the other species available in the NBPR-Wheat. Out of 177 addition lines, 24 belonged to homoeologous group-1 chromosome of wild species. Out of 24 homoeologous group1 chromosome addition lines four addition lines, Agropyron intermedium (haploid genome EStVx), Ag. elongatum (E), Aegilops longissima $\left(\mathrm{S}^{1}\right)$ or Ae. peregrina (US'), were selected and studied in detail (Table 1). Ag. elongatum, Ae. longissima and Ae. peregrina addition lines were produced in the genetic background of cultivar 'Chinese Spring', and the Ag. intermedium addition line in the background of European cultivar 'Vilmorin 27'. In addition, an alloplasmic common wheat line with an Ag. intermedium ssp. trichophorum (EStVx) cytoplasm was also included as an addition line (Table 1). This line segregated in the backgrounds of 'Chinese Spring' and cv. 'Penjamo 62'. A previous study indicated that plump seeds of this addition line carry either one or two small (midget) Ag. intermedium chromosomes, while shriveled seeds do not (Tsujimoto et al., 1987). Accordingly, plump seeds of this line were used in this study. All lines were studied for three consecutive years from 2003 to 2006 , and grown at Tottori University, Japan, for generation advancement.

Chromosome analysis Mitotic chromosomes were prepared from root tip cells using the acetocarmine squash method and used for fluorescent in situ hybridization (FISH) analysis. Total genomic DNA of Ae. tauschii (D) and pAs1 (D genome-specific sequences) were labeled with flouresciene-12-dUTP or tetramethyl-rhodamine-5-dUTP according to the random primer labeling method. Total genomic DNA of T. durum (AB) was sonicated by autoclaving for $2 \mathrm{~min}$ and used as the blocking DNA to determine the presence of $\mathrm{D}$ genome chromosomes. To determine the number of Ag. intermedium chromosomes, total genomic DNA of Ag. intermedium was similarly labeled. Chromosomes were counterstained with 4', 6diamidino-2-phenylindole (DAPI) and observed using a fluorescent microscope (Olympus BX61). Images were captured using a cooled CCD camera CoolSnap fx (Photometrix).

Analysis of seed storage proteins The composition of glutenin subunits from the endosperm half of the seeds was determined by polyacrylamide gel electrophoresis in the presence of sodium dodecyl sulphate (SDS-PAGE), using $10 \%$ acrylamide according to Smith and Payne (1984) with two modifications. The $\mathrm{pH}$ of the separating gel was changed from 8.8 to 8.6 , and the volume of bisacrylamide was changed from 1.63 to $2.08 \mathrm{ml}$ to increase the resolution. (Garg et al., 2007).

\section{RESULTS}

Glutenin seed storage protein pattern of 177 addition lines available in NBPR-wheat was analyzed using SDSPAGE. Out of 177 lines, 24 seemed to carry the alien chromosome belonging to homoeologous group-1 because they carried additional alien HMW glutenin subunits. SDS-PAGE patterns of five of these lines showed unexpected electrophoretic patterns, i.e., missing of the subunits encoded by the genes on chromosome 1D. No absence of the subunits of chromosome $1 \mathrm{~A}$ or $1 \mathrm{~B}$ were recognized.

The SDS-PAGE pattern of the Ag. intermedium chromosome 1Agi (1E) addition line in the background of 'Vilmorin 27' showed additional HMW glutenin subunits $\mathrm{x}$ and $\mathrm{y}$ coded by the Ag. intermedium chromosome (Fig. $1 \mathrm{~A}$, indicated by arrows). One of four seeds tested showed loss of these additional subunits. In all seeds, 3 +12 subunits coded by $\mathrm{x}$ - and y-type genes in the Glu-1 loci on the $1 \mathrm{D}$ chromosome of 'Vilmorin 27' were missing

Table 1. List of alien chromosome addition lines showing preferential substitution of chromosome 1D of wheat with an alien chromosome

\begin{tabular}{|c|c|c|c|c|c|c|c|}
\hline Accession No. & Wild species & Background & $\begin{array}{l}\text { Alien } \\
\text { chromosome }\end{array}$ & Cytoplasm & $\begin{array}{l}\text { Original } \\
\text { chromosome } \\
\text { addition }\end{array}$ & $\begin{array}{l}\text { Changed } \\
\text { chromosome } \\
\text { constitution }\end{array}$ & Reference \\
\hline TACBOW 0034 & Ag. intermedium & Vilmorin 27 & 1Agi (1E) & wheat & $42+2$ & $40+2^{*}+2$ & Cauderon et al. (1973) \\
\hline TACBOW 0038 & Ag. elongatum & Chinese Spring & $1 \mathrm{E}$ & wheat & $42+2$ & $40+2$ & Dvorak and Knott (1974) \\
\hline TACBOW 0269 & Ae. peregrina & Chinese Spring & $1 S^{v}$ & wheat & $42+2$ & $40+2$ & Yang et al. (1996) \\
\hline KSU Ta\#3633 & Ae. longissima & Chinese Spring & $1 \mathrm{~S}^{1}$ & wheat & $42+2$ & $40+2$ & Waines, unpublished \\
\hline $6 \mathrm{H} 1447$ & Ag. intermedium & CS/Penjamo 62 & 1Agi & Ag. intermedium & $42+1 / 2^{*}$ & $41 / 42+1 / 2^{*}$ & Tsujimoto et al. (1987) \\
\hline
\end{tabular}

*Chromosomes are shorter than regular ones 


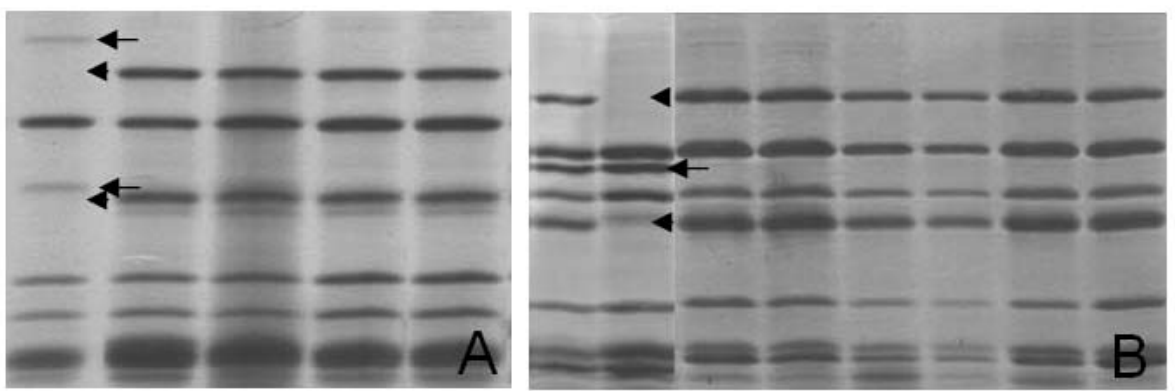

$1 S^{\vee} 1 S^{\vee} 2 S^{\vee} 3 S^{\vee} 4 S^{\vee} 5 S^{\vee} 6 S^{\vee} 7 S^{\vee} \quad 3630363136323633363436353636$
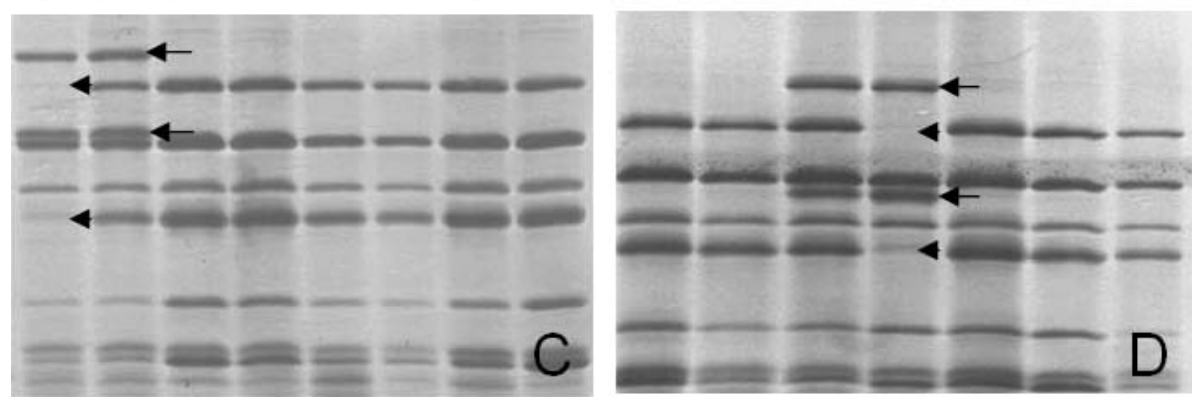

Fig. 1. SDS-PAGE of seed storage proteins in accessions registered as 'addition lines'. A: Disomic 'addition' lines of Ag. intermedium chromosomes. Bands of the alien chromosome appeared in line 1Agi (arrows), but bands $3+12$ of chromosome $1 \mathrm{D}$ of 'Vilmorin 27' wheat were absent in some of the seeds of line 1Agi (arrowheads in the second lane). B: Disomic 'addition' lines of Ag. elongatum. Bands of the alien chromosomes appeared in line $1 \mathrm{E}$ (arrows), but bands $2+12$ were missing in some of the seeds (arrowheads in the second lane). C: Disomic 'addition' lines of Ae. peregrina. Bands of the alien chromosomes appeared in line $1 \mathrm{~S}^{\mathrm{v}}$ (arrows), but bands $2+12$ were absent in some of the seeds (arrowheads in the first lane). D: Disomic 'addition' lines of Ae. longissima. Bands of the alien chromosome appeared in two lines, KSU 3632 and KSU 3633 (arrows), but KSU 3633 did not show bands $2+12$ of chromosome 1D of 'Chinese Spring' wheat (arrowheads in the fourth lane).

(Fig. 1A, indicated by arrowheads). Forster et al. (1987) reported the presence of the Glu-D1-specific bands in same addition line. Most probably these subunits were eliminated during transfer from one generation to another. FISH analysis using total genomic DNA of Ae. tauschii and pAs1 revealed the presence of $14 \mathrm{D}$ genome chromosomes (Fig. 2A), but chromosome 1D was obviously shorter in length than the regular $1 \mathrm{D}$ chromosome (Fig. 2A, indicated by red arrows, Table 1), indicating loss of a part of the chromosome, and thereby, loss of the HMW glutenin locus in this line.

Similar loss of $2+12$ HMW glutenin subunits coded by $\mathrm{x}$ - and y-type genes in the Glu-1 loci on the chromosome $1 \mathrm{D}$ of 'Chinese Spring' was observed in some seeds of the Ag. elongatum addition line 1E (Fig. 1B, indicated by arrow heads). For two consecutive years, Glu-D1 locusspecific subunits were observed, but in the third year, 56 of 122 seeds analyzed had lost these subunits. FISH analysis using total genomic DNA of Ae. tauschii and pAs1 showed $12 \mathrm{D}$ genome chromosomes rather than the expected 14 (Fig. 2B). This suggests loss of a pair of 1D chromosomes in this line, and thereby, loss of the HMW glutenin locus.
The addition line of Ae. peregrina with chromosome $1 \mathrm{~S}^{\mathrm{v}}$ showed additional HMW glutenin subunits in all seeds tested (Fig. 1C, indicated by arrows), but in four of the seven seeds $2+12$ subunits coded by Glu-D1 of 'Chinese Spring' were missing (Fig. 1C, indicated by arrow heads). FISH analysis using total genomic DNA of Ae. tauschii and pAs1 showed $12 \mathrm{D}$ genome chromosomes rather than the expected 14 (Fig. 2C, Table 1). As above, this suggests loss of a pair of $1 \mathrm{D}$ chromosomes, thereby resulting in loss of the HMW glutenin locus.

Several sets of Ae. longissima chromosome addition lines are available; however, chromosome assignment of most of these lines is yet to be completed. These lines were introduced with numbers KSU 3630 to 3636 (Fig. 1D), but no lines except 3635 germinated. Two lines (3632 and 3633) carried additional HMW glutenin subunits in their SDS-PAGE patterns (Fig. 1D, lanes 3 and 4 , indicated by arrows), but in addition line 3633, $2+12$ subunits coded by chromosome 1D of 'Chinese Spring' were missing (Fig. 1D, lane 4, indicated by arrowheads).

The alloplasmic common wheat addition line with the Ag. intermedium ssp. trichophorum cytoplasm did not possess any extra HMW glutenin subunits coded by the 


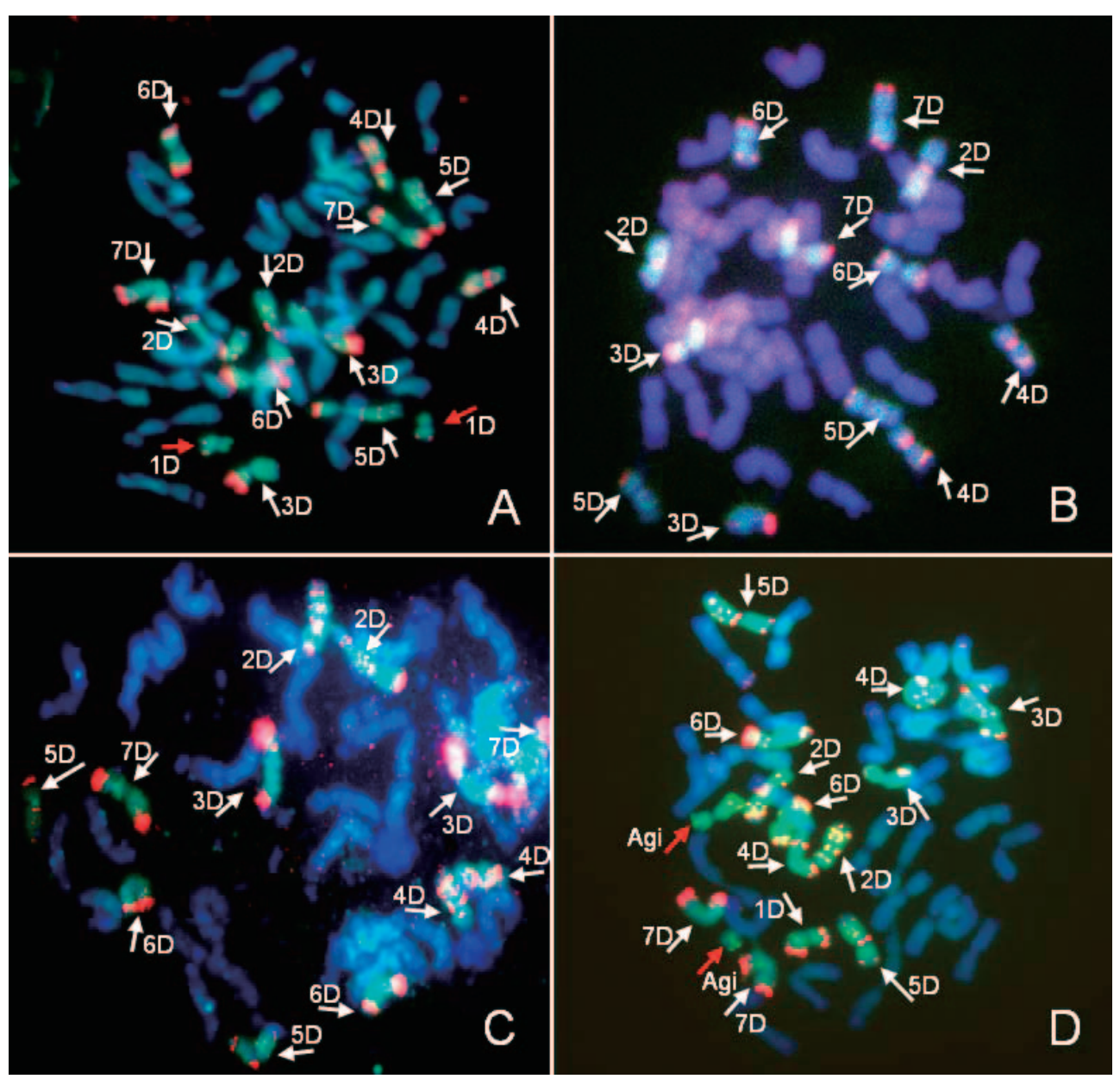

Fig. 2. Fluorescent in situ hybridization (FISH) of chromosomes from lines registered as alien chromosome 'addition' lines probed by genomic DNA of Aegilops tauschii (in green) and pAs1, a D genome-specific repetitive sequence (in red). In figure D the genomic probe of Ag. intermedium (in green) was also hybridized. A: Disomic 'addition' line 1Agi of Ag. intermedium. Twelve normal D-genome chromosomes and two 1D chromosomes with a deletion are indicated by white and red arrows, respectively. B: Disomic 'addition' line of Ag. elongatum. Only 12 D-genome chromosomes were recognized (white arrows), and a pair of $1 \mathrm{D}$ chromosomes were missing. C: Disomic 'addition' line of Ae. peregrina chromosome $1 \mathrm{~S}^{\mathrm{v}}$. Only $12 \mathrm{D}$-genome chromosomes were recognized (white arrows), and a pair of $1 \mathrm{D}$ chromosomes were missing. D: Chromosomes from a plant of the alloplasmic line containing the Ag. intermedium cytoplasm. Thirteen D-genome chromosomes (white arrows) and one full and one telocentric chromosome of Ag. intermedium (red arrows) were recognized.

Ag. intermedium chromosome, and the alien chromosome was thought to belong to the St or Vx genome without any HMW glutenin locus. As there was no HMW glutenin indicating the presence of Ag. intermedium chromosomes, we carried out FISH analysis using probes of total genomic DNAs of Ae. tauschii and Ag. intermedium and pAs1, D-genome preferential repetitive sequence, to determine the number of $\mathrm{D}$-genome and $\mathrm{Ag}$. intermedium chromosomes. Although the HMW glutenin profiles of all seeds studied were similar, FISH images showed the presence of 13 to $14 \mathrm{D}$ genome chromosomes, and different numbers of Ag. intermedium chromosomes in different seeds (Table 1 and 2, Fig. 2D, shown by white and red arrows, respectively).
Table 2. Variable numbers of $\mathrm{D}$ genome and Ag. intermedium chromosomes in different plants of an alloplasmic common wheat line containing the Ag. intermedium ssp. trichophorum cytoplasm

\begin{tabular}{cccc}
\hline \multirow{2}{*}{ Plant number } & \multicolumn{3}{c}{ Number of chromosomes in the genome } \\
\cline { 2 - 4 } & A and B & D & Agi* \\
\hline $6 \mathrm{H} 1447-6$ & 28 & 14 & 1 \\
$6 \mathrm{H} 1447-7$ & 28 & 14 & $1+\mathrm{t}^{* *}$ \\
$6 \mathrm{H} 1447-9$ & 28 & 14 & $1+\mathrm{t}^{* *}$ \\
$6 \mathrm{H} 1447-13$ & 28 & 13 & $1+\mathrm{t}^{* *}$ \\
$6 \mathrm{H} 1447-15$ & 28 & 14 & $2 \mathrm{t}^{* *}$ \\
\hline
\end{tabular}

* Agi indicates one of the genomes of Ag. intermedium

** indicates a telosomic chromosome 


\section{DISCUSSION}

This study revealed that some lines registered as alien chromosome addition lines of homoeologous chromosome 1 lost one or a pair of $1 \mathrm{D}$ chromosomes of common wheat. Common wheat is known to show, in low frequency, unpaired chromosomes in first meiotic metaphase cells, that induces anueploids in the offspring. It is assumed that the examined addition lines also produced such unpaired chromosomes, and that gametes lacking one chromosome were the result. In this case, pollen lacking one of the homoeologous group- 1 chromosomes seems to be advantageous to the majority of pollen carrying 22 chromosomes from the addition lines, because the alien chromosome of group 1 can compensate for the function of the eliminated group- 1 chromosome of common wheat and cancel the deleterious effect of aneuploidy. However, this does not explain why only plants without chromosome 1D appear, instead of those lacking chromosome 1A or $1 \mathrm{~B}$. Even $1 \mathrm{~S}^{1}$ and $1 \mathrm{~S}^{\mathrm{v}}$ of Ae. longissima and Ae. peregrina, respectively, were substituted for chromosome 1D even though both the $\mathrm{S}^{1}$ and $\mathrm{S}^{\mathrm{v}}$ genomes of these species are related to the $\mathrm{S}$ genome of Ae. speltoides, the most reliable B genome donor species of polyploid wheat. Species in the genus Agropyron are distantly related to Aegilops and Triticum, and thus, the relatedness of Agropyron species from the A, B and D genomes of wheat are likely to be similar (Mujeeb-Kazi and Rajaram, 2002). But, also in these cases, only chromosome 1D was substituted by the alien chromosomes.

One of the reasons why $1 \mathrm{D}$ is preferentially substituted by the alien chromosome is that chromosome $1 \mathrm{D}$ is the shortest of all chromosomes in common wheat (Gill et al., 1991), its length representing 76 and $71 \%$ of that of chromosome $1 \mathrm{~A}$ and $1 \mathrm{~B}$, respectively. Since short chromosomes tend to make less chiasmata, they may be more easily eliminated after formation of a univalent.

The second possible reason is related to the evolution of common wheat. The estimated age of wild tetraploid wheat ( $T$. dicoccoides, AABB) is around > 0.5 MYA (Huang et al. 2002 b) to 0.25-1.3 MYA (Mori et al., 1995; Huang et al., 2002 a), or 0.36 MYA (Dvorak and Akhunov, 2005). The A genome of tetraploid wheat diverged from T. urartu less than half a million years ago. After its divergence from $T$. urartu, A genome in polyploid wheat underwent many changes as a result of exchange of genetic material (Huang et al., 2002b). Species-specific translocations involving chromosome 4A-5A-7B intergenomic translocations have been found in emmer wheat (Naranjo, 1990; Liu et al., 1992). There may be more translocations of this kind involving the $\mathrm{A}$ and $\mathrm{B}$ genomes, which are yet to be found. Certain important parts of an involved chromosome might be translocated to another chromosome. Deficiencies of such chromosomes might be deleterious to the plant. However, despite this, the chances of such translocation between the A or B and $\mathrm{D}$ genomes of common wheat are less likely because the period of origin of hexaploid wheat is relatively recent, around 8,000 years ago (McFadden and Sears, 1946). The sequences of $\mathrm{D}$ genome-specific genes in T. aestivum and Ae. tauschii are reportedly identical (Huang et al., 2002b), confirming that after its divergence from Ae. tauschii, the $\mathrm{D}$ genome in polyploid wheat did not undergo any big changes as a result of exchange of genetic material. It is therefore easier for hexaploid wheat to substitute D genome chromosomes with alien chromosomes, without having any deleterious effect on the plant compared to substitutions associated with loss of the A or $\mathrm{B}$ genome.

The third possible reason is based on the presence of an inferior gene related to the speed of pollen tube elongation on chromosome 1D. Tsujimoto (2001) identified a translocated chromosome between the $1 \mathrm{D}$ of wheat and $1 \mathrm{C}$ of Ae. caudata (T1CS.1CL-1DL). This chromosome appeared spontaneously in progeny of a hybrid between both species (Kihara, 1951), and was transmitted preferentially from the male side. Chromosome 1C of Ae. caudata must therefore have a superior gene(s) related to the speed of pollen tube elongation.

Chromosome 1D carries important genes related to bread-making quality, i.e. encoding HMW- and low molecular weight glutenins. Thus, substitution of chromosome 1D by an alien chromosome and loss of many of these useful genes is not desirable. Alien chromosome carrying useful genes for bread-making character should be replaced by chromosome $1 \mathrm{~A}$ that possesses small or even negative effect (Garg et al., 2007). In this sense, we need to pay much attention to this spontaneous replacement of chromosome 1D by alien chromosomes in management of alien chromosome addition stocks.

This study was partly supported by Grant-in-Aid from the Ministry of Education, Culture, Sports, Science and Technology, Japan (No. 19380006).

\section{REFERENCES}

Cauderon, Y., Saigne, B., and Dauge, M. (1973) The resistance to wheat rusts of Agropyron intermedium and its uses in wheat improvement. Proc. $4^{\text {th }}$ Int. Wheat Genet. Symp. Columbia, MO, 401-407.

Dou, Q. W., Tanaka, H., Nakata, N., and Tsujimoto, H. (2006) Molecular cytogenetic analyses of hexaploid lines spontaneously appearing in octoploid Triticale. Theor. Appl. Genet. 114, 41-47.

Dvorak, J., and Akhunov, E. (2005) Tempos of gene locus deletions and duplications and their relationship to recombination rate during diploid and polyploid evolution in the Aegilops-Triticum alliance. Genetics 171, 323-332.

Dvorak, J., and Knott, D. R. (1974) Disomic and ditelosomic additions of diploid Agropyron elongatum chromosomes to Triticum aestivum. Can. J. Gen. Cytol. 16, 399-417.

Forster, B. P., Reader, S. M., Forsyth, S. A., Koebner, R. M. D., 
Miller, T. E., Gale, M. D., and Cauderon, Y. (1987) An assessment of the homoeology of six Agropyron intermedium chromosomes added to wheat. Genet. Res. Camb. 50, 9197.

Garg, M., Dhaliwal, H. S., Chhuneja, P., Kumar, D., Dou, Q.-W., Elamein, H. M. M., Tanaka, H., and Tsujimoto, H. (2007) Negative effect of chromosome 1A on dough strength shown by modification of $1 \mathrm{D}$ addition in durum wheat (Triticum durum). Theor. Appl. Genet. 114, 1141-1150.

Gill, B. S., Friebe, B., and Endo, T. R. (1991) Standard karyotype and nomenclature system for description of chromosome bands and structural aberration in wheat (Triticum aestivum). Genome 34, 830-839.

Huang, S., Sirikhachornkit, A., Su, X., Faris, J., Gill, B., Haselkorn, R., and Gornicki, P. (2002a) Phylogenetic analysis of the acetyl-CoA carboxylase and 3-phosphoglycerate kinase loci in wheat and other grasses. Plant Mol. Biol. 48, $805-820$.

Huang, S., Sirikhachornkit, A., Su, X., Faris, J., Gill, B., Haselkorn, R., and Gornicki, P. (2002b) Genes encoding plastid acetyl-CoA carboxylase and 3-phosphoglycerate kinase of the Triticum/Aegilops complex and the evolutionary history of polyploidy wheat. Proc. Natl. Acad. Sci. USA 99, 8133-8138.

Kihara, H. (1951) Substitution of nucleus and its effects on genome manifestations. Cytologia 16, 177-193.

Liu, C. J., Atkinson, M. D., Chinoy, C. N., Devos, K. M., and Gale, M. D. (1992) Nonhomoeologous translocation between group 4, 5 and 7 chromosomes within wheat and rye. Theor. Appl. Genet. 83, 305-312.

Lawrence, G. J., and Shepherd, K. W. (1981) Chromosomal locations of genes controlling seed proteins in species related to wheat. Theor. Appl. Genet. 59, 25-31.
McFadden, E. S., and Sears, E. R. (1946) The origin of Triticum speltoides and its free-threshing hexaploid relatives. J. Hered. 37, 81-89.

Mori, N., Liu, Y.-G., and Tsunewaki, K. (1995) Wheat phylogeny determined by RFLP analysis of nuclear DNA. 2. Wild tetraploid wheats. Theor. Appl. Genet. 90, 129-134.

Mujeeb-Kazi, A., and Rajaram, S. (2002) Transferring alien genes from related species and genera for wheat improvement. In: FAO Plant Production and Protection Series, Bread Wheat, Improvement and Production (eds. B. C. Curtis, S. Rajaram, and H. Gómez Macpherson), pp. 567. FAO, Fiale delle Termed i Caracalla.

Naranjo, T. (1990) Chromosome structure of durum wheat. Theor. Appl. Genet. 79, 397-400.

Nieto-Taladriz, M. T., Perretant, M. R., and Rousset, M. (1994) Effect of gliadins and HMW and LMW subunits of glutenin on dough properties in the $\mathrm{F}_{6}$ recombinant inbred lines from a bread wheat cross. Theor. Appl. Genet. 88, 81-88.

Smith, D. B., and Payne, P. I. (1984) A procedure for the routine determination of electrophoretic band patterns of barley and malt endosperm proteins. J. Nat. Ins. Agri. Bot. 16, 487498.

Tsujimoto, H. (2001) Production of near-isogenic lines and marked monosomic lines in common wheat (Triticum aestivum) cv. Chinese Spring. Heredity 92, 254-259.

Tsujimoto, H., Panayotov, I., and Tsunewaki, K. (1987) Behavior of an extra chromosome carried by alloplasmic common wheat lines having Agropyron trichophorum cytoplasm. Jpn. J. Genet. 62, 291-299.

Yang, Y. C., Tuleen, N. A., and Hart, G. E. (1996) Isolation and identification of Triticum aestivum L. em. Thell. cv. Chinese Spring-T. peregrinum Hackel disomic chromosome addition lines. Theor. Appl. Genet. 92, 591-598. 